\title{
A comparative study of Energy Saving Technical Progress in a Vintage Capital Model.*
}

\author{
Discussion Paper version \\ Agustín Pérez - Barahona †and Benteng Zou \\ Université catholique de Louvain \\ 18th February 2004
}

\begin{abstract}
We analyzed the hypothesis about the effectiveness of energy saving technologies to reduce the trade-off between economic growth and energy preservation. In a general equilibrium vintage capital model with embodied energy saving technical progress, we show that the success of energy saving technologies is questionable in a scenario of decreasing energy supply. Only constant returns to scale, with constant energy supply, yields long run growth.
\end{abstract}

Keywords: Nonrenewable resources, Energy saving technological progress, Vintage capital.

Journal of Economic Literature: C68, O31, O41, Q32, Q43

${ }^{*}$ We acknowledge the financial support of the Belgian French speaking community (Grant ARC 99/04-235 "Growth and incentive design") and of the Belgian Federal Government (Grant PAI P5/10, "Equilibrium theory and optimization for public policy and industry regulation"). A. Pérez-Barahona recognizes the financial support of the Fundación Caja Madrid and the Fundación Caixagalicia. Authors also appreciate Raouf Boucekkine and Ramón Tamariz for their valuable comments. Any remaining errors is ours.

${ }^{\dagger}$ Corresponding author. IRES, Université catholique de Louvain, Place Montesquieu, 3, B-1348 Louvain-la-Neuve (Belgium) Tel. +32 10473572 E-mail: perez@ires.ucl.ac.be 


\section{Introduction}

Fossil fuel - in particular petroleum and its refinery products - is an essential input throughout all modern economies. However, the reduced availability of this basic element in production and the stabilization of greenhouse gases concentration would have a negative impact in economic growth and development, through cutbacks in energy use (Smulders and de Nooij (2003); see Xepapadeas (2003) for an overview of economic growth and pollution). As a consequence, we can a priori ensure a trade-off between energy reduction and growth. Nevertheless, this trade-off could be less severe if energy conservation is raised by energy saving technologies. Carraro, Gerlagh and van der Zwaan (2003) pointed out that hypothesis, since new technologies can fundamentally alter the extent and nature of this trade-off. Moreover, it is well known that the effect of public policies on the development and spread of new technologies is among one of the crucial determinants of the success or failure of environmental management (see Löschel (2002), for a survey). Newell, Jaffe and Stavins (1999) studied whether the increase in the energy cost in recent years induces energy savings innovation in the US; they concluded that the induced innovation hypothesis is very reasonable.

We focus on the exhaustion problem of fossil fuel, considering the energy saving technological progress as a way to offset the negative effect of energy cutbacks. A general equilibrium model is developed here, based on Boucekkine, Germain and Licandro (1997). We take an economy with exogenous technological progress embodied in the new capital goods, which are introduced through a vintage capital technology with endogenous obsolescence (scrapping) rule. A comparative study is developed in order to contrast constant and decreasing returns to scale, within two possible scenarios: constant (optimistic) and decreasing (gloomy) exogenous energy supply. We get that, under the existence of balance growth path (BGP) defined by constant growth rate of all the endogenous variables, only the case of constant returns to scale, in the optimistic scenario, yields compatibility between energy reduction and growth. Otherwise, our economy does not present growth along the BGP.

The paper is organized as follows. In section 2, we describe the general case model, with the representative consumer's problem and the rules that depicts both the optimal investment and the scrapping behavior of the firms. The BGP is presented in section 3, where we show the necessary conditions for its existence in both constant and decreasing returns to scale. Finally, some concluding remarks are considered in section 4 . 


\section{The Model}

Following Boucekkine et al. (1997), we consider an economy where the population is constant. There is only one final good (numeraire good) which can be assigned to consumption or investment. The final good is produced in a competitive market by a constant returns to scale technology, which is defined over a continuum of inputs in the interval $[0,1]$. Inputs are produced by mean of a technology defined over vintage capital. Both constant and decreasing returns to scale are considered here. The input market is assumed monopolistically competitive to allow for a concave profit function in inputs sector. Also, we assume competitive labour market and exogenous available energy supply.

\section{$2.1 \quad$ Individual's behavior}

Let us assume that the representative household considers the following standard inter-temporal maximization problem with constant relative risk aversion (CRRA) instantaneous utility function

$$
\max _{c(t), a(t)} \int_{0}^{\infty} \frac{c(t)^{1-\theta}}{1-\theta} e^{-\rho t} d t
$$

subject to the budget constraint

$$
\begin{gathered}
\dot{a}(t)=r(t) a(t)-c(t) \\
a(0) \text { given } \\
\lim _{t \rightarrow \infty} a(t) e^{-\int_{0}^{t} r(z) d z}=0
\end{gathered}
$$

with initial wealth $a_{0}$, where $c(t)$ is per-capita consumption, $a(t)$ is per-capita asset held by and the interest rate $r(t)$ is taken as given for the household. $\theta$ measures the constant relative risk aversion, and $\rho$ is the time preference parameter (it is assumed positive discount factor). The corresponding necessary conditions are $r(t)=\rho+\theta \frac{\dot{c}(t)}{c(t)}$, with $\lim _{t \rightarrow \infty} \lambda(t) a(t)=0$, where $\lambda(t)$ is the co-state variable associated with the wealth accumulation equation.

\section{$2.2 \quad$ Final Good Firm}

The final good is produced competitively by a representative firm by solving the following optimal profit problem

$$
\max _{y_{j}(t)}\left\{y(t)-\int_{0}^{1} p_{j}(t) y_{j}(t) d j\right\}
$$


where the per-capita production $y(t)$ is given by a constant elasticity of substitution (CES) production technology

$$
y(t)=\left(\int_{0}^{1} y_{j}(t)^{\frac{\epsilon-1}{\epsilon}} d j\right)^{\frac{\epsilon}{\epsilon-1}}
$$

defined over a continuum of inputs $y_{j}(t)$ with $j \in[0,1]$. It is assumed a constant elasticity of substitution $\epsilon>1$. Prices are given by

$$
p_{j}(t)=\left(\frac{y_{j}(t)}{y(t)}\right)^{-\frac{1}{\epsilon}}
$$

which comes from the standard monopolistic competition economy (Dixit and Stiglitz (1977)) and they are taken as given by the final good firm.

\subsection{Input firm}

Producing in a monopolistically competitive market, the representative input $j$ firm maximizes her profits

$$
\max _{y_{j}(t), i_{j}(t), T_{j}(t), p_{j}(t)} \int_{0}^{\infty} e^{-r(t) t}\left[p_{j}(t) y_{j}(t)-i_{j}(t)-e_{j}(t) P e(t)(1+Z)\right] d t
$$

subject to

$$
\begin{gathered}
y_{j}(t)=A\left(\int_{t-T_{j}(t)}^{t} i_{j}(z) d z\right)^{\alpha}, 0<\alpha \leq 1 \\
e_{j}(t)=\int_{t-T_{j}(t)}^{t} i_{j}(z) e^{-\gamma z} d z, \quad 0<\gamma<r \\
p_{j}(t)=\left(\frac{y_{j}(t)}{y(t)}\right)^{-\frac{1}{\epsilon}}
\end{gathered}
$$

with the initial conditions $i(t)$ given for all $t \leq 0$, where $e_{j}(t)$ and $P_{e}(t)$ are respectively the demand and the price of energy, which are endogenous. $Z$ is the expenditure energy tax defined by the government ${ }^{1} . i_{j}(t)$ is the investment of the representative input $j$ firm. The output and the price for input $j$ are respectively represented by $y_{j}(t)$ and $p_{j}(t)$. The price of input $j$ and the final good production per-capita, $y(t)$, are taken as given by the monopoly. The equation (7) is our technology defined over vintage capital. The energy demand is obtained by the equation (8). Here $\gamma>0$

\footnotetext{
${ }^{1}$ It could be considered as a lump-sum tax.
} 
represents the rate of energy saving technological progress and $T_{j}(t)$ is the age of the oldest operating machines or scrapping age. Considering monopolistic competition, the inverse demand function is given by the equation (9).

Notice that the new technology is more energy saving. Moreover, it is important to observe that we assume complementarity between capital and energy (Leontieff technology). Certainly, each vintage $i_{j}(t)$ has an energy requirement $i_{j}(t) e^{-\gamma t}$. This assumption is unfailing from numerous studies; for instance Hudson and Jorgenson (1974), or Berndt and Wood (1975).

We define the capital stock

$$
K(t)=\int_{t-T(t)}^{t} i(z) d z
$$

and the optimal life of machines of vintage $t$

$$
J_{j}(t)=T_{j}\left(t+J_{j}(t)\right)
$$

Notice that

$$
T_{i}(t)=J_{i}\left(t-T_{i}(t)\right)
$$

Let us consider the symmetric equilibrium ${ }^{2}$. From the first order condition (FOC) for $i(t)$, we get the optimal investment rule

$$
\begin{gathered}
\int_{t}^{t+J(t)} \alpha A\left(\int_{\tau-T(\tau)}^{\tau} i(z) d z\right)^{\alpha-1} e^{-\int_{t}^{\tau} r(z) d z} d \tau= \\
1+\int_{t}^{t+J(t)}(1+Z) P_{e}(\tau) e^{-\gamma t} e^{-\int_{t}^{\tau} r(z) d z} d \tau
\end{gathered}
$$

where the left hand side (LHS) is the discounted marginal productivity during the whole lifetime of the capital acquired in $t ; 1$ is the marginal purchase cost at $t$, normalized to one; and the second term on the right hand side (RHS) is the discounted operation cost at $t$.

The optimal investment rule establishes that firms should invest at time $t$ until the discounted marginal productivity during the whole lifetime of the capital acquired in $t$ exactly compensates for both its discounted operation cost and its marginal purchase cost at $t$.

From the FOC for $T(t)$, we have the optimal scrapping rule

$$
A \alpha\left(\int_{t-T(t)}^{t} i(z) d z\right)^{\alpha-1}=P_{e}(t)(1+Z) e^{-\gamma(t-T(t))}
$$

\footnotetext{
${ }^{2} y_{j}(t)=y(t), T_{j}(t)=T(t), J_{j}(t)=J(t), p_{j}(t)=1, i_{j}(t)=i(t)$ and $e_{j}(t)=e(t)$.
} 
The optimal scrapping rule states that a machine should be scrapped as soon as its marginal productivity (which is the same for any machine whatever its age) no longer covers its operation cost (which rises with its age).

Here the marginal productivity is given by $\alpha A\left(\int_{t-T(t)}^{t} i(z) d z\right)^{\alpha-1}$, and $(1+Z) P_{e}(t) e^{-\gamma(t-T(t))}$ represents the operation cost.

\subsection{Decentralized equilibrium}

The (decentralized) equilibrium of our economy is characterized by equations (2), necessary and transversality condition of the household problem, equations (7)-(11), the optimal investment rule, the optimal scrapping rule, and the following three additional equations to close the model: $c(t)+i(t)=y(t)$, $i(t)=\dot{a}(t)$ and $e(t)=e_{s}(t)$, the equilibrium condition in the energy market. $e_{s}(t)$ is the available energy supply ${ }^{3}$; in our model it is assumed exogenous.

\section{Balanced growth paths}

Let us define the balance growth path (BGP) equilibrium as the situation where all endogenous variables grow at constant rate. Boucekkine et al. (1998) considered an equivalent model to our case of constant returns to scale $(\alpha=1)$. Following Malcomson (1975), they presented a sufficient condition for the existence of a particular BGP with both constant scrapping age and constant available energy supply ${ }^{4}$. Nevertheless, for the case of decreasing returns to scale $(0<\alpha<1)$, we got that an analytical prove of existence of such a BGP, using Malcomson's technique, is not possible ${ }^{5}$ (Pérez-Barahona and Zou (2003)). Moreover, it is not difficult to check that an alternative BGP, with not constant scrapping age, is not compatible with constant growth of the other endogenous variables.

As a consequence, in order to compare constant and decreasing returns to scale, we assume the existence of BGP with constant scrapping age ${ }^{6} T(t)=$

\footnotetext{
${ }^{3}$ The available energy supply is a flow (exogenous) variable, for example petrol or any petroleum refinery product to generate energy. Here we do not explicitly treat extraction sector either producer countries.

${ }^{4}$ They assumed a technology that saves labour instead of energy saving technological progress. A constant (exogenous) labour supply were considered.

${ }^{5}$ Observe that $T(t)$ is forward-looking, but it depends on its own value in a particular and endogenous point of time. This type of variable is not standard in economic models.

${ }^{6}$ Such an equilibrium (Terborgh-Smith result) is well known in economic literature. For example, P.K. Bardhan (1969) and Boucekkine et al.(1997).
} 
$J(t)=\bar{T}$. In the following, we present the necessary conditions of our BGP for both, constant and decreasing returns to scale.

\subsection{Necessary Conditions}

For the general case $0<\alpha \leq 1$, we get from the necessary condition of the household problem and along the BGP

$$
r(t)=\rho+\theta \gamma_{c}=\text { constant }=r^{*}
$$

and

$$
e^{-\int_{t}^{\tau} r(z) d z}=e^{-r^{*}(\tau-t)}
$$

where $\gamma_{c}$ is the growth rate of consumption.

Differentiating (13) and rearranging terms, we obtain by (14)

$$
\left(e^{\gamma T}-1\right)-\frac{\gamma}{\gamma_{P_{e}}-r^{*}}\left(e^{\left(\gamma_{P_{e}}-r^{*}\right) J}-1\right)=\frac{r^{*}}{(1+Z) \bar{P}_{e}} e^{\gamma-\gamma_{P_{e}} t}
$$

where $\gamma_{P_{e}}$ and $\bar{P}_{e}$ are respectively the growth rate and the level of the energy prices. The LHS is constant for any $t$ in the BGP, and the right hand side RHS is a function of $t$. So the equality holds if and only if

$$
\gamma=\gamma_{P_{e}}
$$

As in the standard growth model, this result states that energy prices grow at the same rate as productivity, in terms of energy saving.

By the definition of $K(t)$, we have along the BGP that

$$
K(t)= \begin{cases}\frac{\bar{i}}{\gamma_{i}}\left(1-e^{-\gamma_{i} \bar{T}}\right) e^{\gamma_{i} t} & \text { if } \gamma_{i}>0 \\ i^{*} \bar{T} & \text { if } \gamma_{i}=0\end{cases}
$$

where $i(t)=\bar{i} e^{\gamma_{i} t}$. Then, the growth rate of investment $\left(\gamma_{i}\right)$ and capital stock $\left(\gamma_{K}\right)$ are equal.

Moreover, by (14) and (18)

$$
A \alpha K(t)^{\alpha-1}=(1+Z) \overline{P_{e}} e^{\gamma \bar{T}}
$$

where $P_{e}(t)=\bar{P}_{e} e^{\gamma \bar{T}}$. Substituting (19) into (20) it yields

$$
e^{\gamma_{i}(\alpha-1) t}=\frac{(1+Z) \overline{P_{e}} e^{\gamma \bar{T}}}{A \alpha \bar{K}^{\alpha-1}}
$$


It is easy to see that (21) holds if and only if $\alpha=1$ and/or $\gamma_{i}=0$. Then, at this point, we have to distinguish between constant and decreasing returns to scale. If we have decreasing returns to scale $(0<\alpha<1)$ then $\gamma_{i}=0$. However, for the case of constant returns to scale $(\alpha=1) \gamma_{i}$ is undetermined a priori.

\subsubsection{Constant returns to scale}

From equation (8) we get the energy demand along the BGP

$$
e(t)=\frac{i(t)}{\gamma} e^{-\gamma t}\left(e^{\gamma \bar{T}}-1\right)
$$

If we assume that the energy market is in equilibrium along the BGP, energy demand equals energy supply $\left(e_{s}(t)\right)$. We make a distinction between two possible scenarios. There is an optimist scenario, with constant available energy supply. However, there is a gloomy situation, where the available energy supply is decreasing ${ }^{7}$.

Case I: Constant available energy supply $e_{s}(t)=\bar{e}_{s}$

Equalizing $e(t)=\bar{e}_{s}$ in equation (22), we get

$$
i(t)=\frac{\bar{e}_{s} \gamma}{e^{\gamma \bar{T}}-1} e^{\gamma t}
$$

Hence, $\gamma_{i}\left(=\gamma_{K}\right)=\gamma$. Moreover, as $y(t)=A K(t)$ then $\gamma_{y}=\gamma_{K}(=\gamma){ }^{8}$

From the budget constraint $y(t)=c(t)+i(t)$, we also achieve that $\gamma_{c}=\gamma \cdot{ }^{9}$

Summarizing, we have the following proposition for the case constant available energy supply:

Proposition 1 Along the balanced growth path, assuming $0<\alpha<1$, $e_{s}(t)=\bar{e}_{s}$ and $\gamma<\rho$,

1. the interest rate $r(t)=r^{*}=\rho+\theta \gamma$;

\footnotetext{
${ }^{7}$ There is not meaning to assume increasing available energy supply, because we are considering resources subject to exhaustion. The most optimistic scenario is constant available energy supply.

${ }^{8}$ From the definition of capital stock is straightforward $K(t)=\gamma^{2} \bar{e}_{s} e^{-\gamma \bar{T}} e^{\gamma t}$. Since $y(t)=A K(t)$, then $y(t)=A \gamma^{2} \bar{e}_{s} e^{-\gamma \bar{T}} e^{\gamma t}$.

${ }^{9} c(t)=\bar{e}_{s} \gamma\left(e^{\gamma \bar{T}} A \gamma-\frac{1}{e^{\gamma \bar{T}}-1}\right) e^{\gamma t}$.
} 
2. the growth rate of energy prices equals the the growth rate of energy saving technological progress $\left(\gamma_{P_{e}}=\gamma\right)$;

3. the growth rate of investment and capital stock are equal to the growth rate of energy saving technological progress $\left(\gamma_{i}=\gamma_{K}=\gamma\right)$;

4. the growth rate of final good output equals the growth rate of energy saving technological progress $\left(\gamma_{y}=\gamma\right)$;

5. the growth rate of consumption equals the growth rate of energy saving technological progress $\left(\gamma_{c}=\gamma\right)$.

Case II: Decreasing energy supply $e_{s}(t)=\bar{e}_{s} e^{-\gamma_{e_{s}} t}$

Equalizing $e(t)=\bar{e}_{s} e^{-\gamma_{e s} t}$ in equation (22), it yields

$$
\frac{i(t)}{\gamma}\left(e^{\gamma \bar{T}}-1\right) e^{-\gamma t}=\bar{e}_{s} e^{-\gamma_{e_{s}} t}
$$

Then, to have BGP the growth rate of energy supply $\left(\gamma_{e_{s}}\right)$ has to equal $\gamma$. This means that the economy chooses a growth rate of energy saving technological progress equalizing the decrease rate of available energy supply. As a consequence:

$$
i(t)=i^{*}=\frac{\bar{e}_{s} \gamma}{\left(e^{\gamma \bar{T}}-1\right)}
$$

Since $\gamma_{i}\left(=\gamma_{K}\right)=0$, from the production function $y(t)=A K(t), \gamma_{y}=\gamma_{K}=$ $0 .{ }^{10}$

From the budget constraint $y(t)=c(t)+i(t), \gamma_{c}=0 .{ }^{11}$

Finally, we get a proposition:

Proposition 2 Along the balanced growth path, assuming $\alpha=1, e_{s}(t)=$ $\bar{e}_{s} e^{-\gamma t}$ and $\gamma<\rho$,

1. the interest rate $r(t)=r^{*}=\rho$;

2. the growth rate of energy prices equals the the growth rate of energy saving technological progress $\left(\gamma_{P_{e}}=\gamma\right)$;

3. there is not growth in investment and capital stock $\left(\gamma_{i}=\gamma_{K}=0\right)$;

\footnotetext{
${ }^{10}$ Hence, $K(t)=K^{*}=\frac{\gamma \bar{e}_{s}}{e^{\gamma \bar{T}}} \bar{T}$ and $y(t)=y^{*}=A \frac{\gamma \bar{e}_{s}}{e^{\gamma \bar{T}}} \bar{T}$.

${ }^{11} c(t)=c^{*}=(A-1) \frac{\gamma \bar{e}_{s}}{e^{\gamma \bar{T}}-1} \bar{T}$.
} 
4. the growth rate of final good output is zero $\left(\gamma_{y}=0\right)$;

5. there is not growth in consumption $\left(\gamma_{c}=0\right)$.

To finish, we have to point out that constant returns to scale, in an optimistic scenario (i.e. $e_{s}(t)=\bar{e}_{s}$ ), generates exogenous growth with the same rate as the growth of (exogenous) energy saving technological progress $(\gamma)$. However, if a pessimistic position is assumed (i.e. $\left.e_{s}(t)=\bar{e}_{s} e^{-\gamma t}\right)$, the positive effect of the energy saving technological progress is completely offset by the decreasing energy supply. Then, since we consider BGP equilibrium with constant scrapping age $T(t)=\bar{T}$, our model does not yield growth in the long run (see equation (24)).

\subsubsection{Decreasing returns to scale}

As before, equation (21) holds if and only if $\alpha=1$ and $/$ or $\gamma_{i}=0$. Since now we consider decreasing returns to scale $(0<\alpha<1)$, the growth rate of investment has to be zero. As a consequence, $\gamma_{K}=0$ because $\gamma_{i}=\gamma_{K}$.

Considering the energy market in equilibrium along the BGP, from equation (22) we conclude that a BGP is only possible in a gloomy scenario (i.e. $\left.e_{s}(t)=\bar{e}_{s} e^{-\gamma t}\right)$. Then

$$
i(t)=i^{*}=\frac{1}{\bar{T}}\left(\frac{(1+Z) \overline{P_{e}} e^{\gamma \bar{T}}}{A \alpha}\right)^{\frac{1}{\alpha-1}}
$$

Since $y(t)=A K(t)^{\alpha}$ and $\gamma_{i}=0$, from equation (19) we get $y(t)=y^{*}=$ $A\left(i^{*} \bar{T}\right)^{\alpha}$. Hence, $\gamma_{y}=0$. Considering the budget constraint along the BGP, it is straightforward $\gamma_{c}=0$.

To sum up, we have the following proposition:

Proposition 3 Along the balanced growth path, assuming $0<\alpha<1$, $e_{s}(t)=\bar{e}_{s} e^{-\gamma t}$ and $\gamma<\rho$,

1. the interest rate $r(t)=r^{*}=\rho$;

2. the growth rate of energy prices equals the the growth rate of energy saving technological progress $\left(\gamma_{P_{e}}=\gamma\right)$;

3. there is not growth in investment and capital stock $\left(\gamma_{i}=\gamma_{K}=0\right)$;

4. the growth rate of final good output is zero $\left(\gamma_{y}=0\right)$; 
5. there is not growth in consumption $\left(\gamma_{c}=0\right)$.

Finally, we have to remark that this case has no growth in the long run. This behavior is explained, on the one hand, by the assumption of decreasing returns to scale in the intermediate good technology; and on the other hand because here we get that both the scrapping age and the exogenous energy saving technological progress are not strong enough to overcome those decreasing returns. The reason is the following. Our framework considers CRRA instantaneous utility function; as a consequence, the interest rate is constant in the long run. Then, consistently with the Terborgh-Smith result, the scrapping age is also constant along the BGP. Taking the optimal investment rule in the long run

$$
\begin{gathered}
\alpha A e^{\rho t} \int_{t}^{t+\bar{T}}\left(\int_{\tau-\bar{T}}^{\tau} i(z) d z\right)^{\alpha-1} e^{-\rho \tau} d \tau= \\
1+(1+Z) \bar{P}_{e} \frac{1}{\rho-\gamma}\left(1-e^{-(\rho-\gamma) \bar{T}}\right)
\end{gathered}
$$

it is straightforward that the discounted operation cost is constant because the effect of the energy saving technological progress $(\gamma)$ is offset by the decreasing available energy supply. Hence, as the marginal purchase cost (1) is remaining constant, the investment has to be also constant along the BGP.

The outcomes of section 3.1.1 (Case II) and section 3.1.2 are not standard results. In the case of neoclassical models, we would have exogenous growth. For example, the models of Solow-Swan and Ramsey, with exogenous technological progress, describe economies which grow at the growth rate of both population and exogenous technological progress. However, we get now that the the reduced availability of energy (nonrenewable resource) offsets the (exogenous) energy saving technological progress. As a consequence, since we consider BGP equilibrium with constant scrapping age, our economy does not present long run growth. This result is consistent with the partial equilibrium model of Boucekkine and Pommeret (2002), which also depicts no growth along the BGP.

\section{Concluding remarks}

We analyzed the hypothesis about the effectiveness of energy saving technologies to reduce the trade-off between economic growth and energy preservation. In order to incorporate the roll of technology replacement, we developed 
a general equilibrium model, where the intermediate goods are produced by a vintage capital technology with endogenous scrapping rule. New vintages obsolete old machines because of their lower energy requirements. Constant and decreasing returns to scale are distinguished to develope a comparative study.

Under constant returns to scale, long run growth is only possible if we are in an optimistic context (constant available energy supply). In this case, the (exogenous) growth rate of the economy equals the (exogenous) growth rate of energy saving technological progress. However, if a gloomy situation is considered (decreasing available energy supply), our economy does not present long run growth. Furthermore, when we assume decreasing returns to scale, the economy achieves BGP only for the pessimistic case. As in the gloomy situation with constant returns to scale, this case does not exhibit growth in the long run. The reason of this incompatibility between long run growth and energy reduction, in both constant and decreasing returns to scale, is that the energy saving technological progress is offset by the decreasing available energy supply. Since BGP equilibrium with constant scrapping age is analyzed, our economy does not yield growth in the long run.

As a conclusion, we have shown a limit to the success of energy saving technologies ${ }^{12}$ as a way to achieve growth and energy conservation. According to our model, energy saving technologies would not be sufficient to deal efficiently with the trade-offs involved in the management of non-renewable resources.

\footnotetext{
${ }^{12}$ See Mulder et al. for another critic about the success of this kind of technology within a vintage capital framework.
} 


\section{References}

Bardhan P. K., 1969, Equilibrium Growth in a model with Economic Obsolescence, The Quarterly Journal of Economics, 83, 312-323.

Berndt E. and Wood D., 1974, Technology, prices and derived demand for energy, The Review of Economics and Statistics, 57, 259-268.

Boucekkine R., Germain, M. and Licandro O., 1996, General Equilibrium Vintage Capital Growth Models Displaying Periodic solutions: A theoretical Example, CORE Discussion Paper, 9632.

Boucekkine R., Germain, M. and Licandro O., 1996, Replacement echoes in the vintage capital growth model, Journal of Economic Theory, 74, 333348 .

Boucekkine R., Germain M., Licandro O. and Magnus A., 1998, Creative Destruction, Investment Volatility and the Average Age of Capital, Journal of Economic Growth, 3, 361-384.

Boucekkine R. and Pommeret A., 2002, Energy Saving Technical Progress and Optimal Capital Stock: the Role of Embodiment, Economic Modelling.

Carraro C., Gerlagh R. and van der Zwaan B., 2003, Endogenous technical change in environmental macroeconomics, Resource and Energy Economics 25, 1-10.

Cass, D., 1965, Optimum Growth in an Aggregative Model of Capital Accumulation, Review of Economic Studies, 32 (July), 233-240.

Dixit A. and Stiglitz J., 1977, Monopolistic Competition and Optimum Product Diversity, American Economic Review, 67, 297-308.

Koopmans T.C., 1965, On the Concept of Optimal Economic Growth, The Econometric Approach to Development Planning, Amsterdam, North Holland.

Löschel A., 2002, Technological change in economic models of environmental policy: a survey, Ecological Economics 43, 105-126.

Malconson J., 1975, Replacement and the Rental Value of Capital Equilibrium subject to Obsolescence, Journal of Economic Theory, 10, 24-41. 
Mulder P., de Groot H.L.F. and Hofkes M.W., 2002, Explaining slow diffusion of energy-saving technologies; a vintage model with returns to diversity and learning by doing, Resource and Energy Economics, 25, 105-126.

Newell R., Jaffe A. and Stavins R., 1999, The Induced Innovation Hypothesis and Energy Saving Technological Change, Quarterly Journal of Economics 114, 941-975.

Pérez-Barahona A. and Zou B., 2003, Energy Saving Technological Progress in a Vintage Capital Model, IRES Discussion Paper, 26.

Ramsey, F., 1928, A Mathematical Theory of Saving, Economic Journal, 38, (December), 543-559.

Smith V.L., 1961, Investment and Production: A Study in the Theory of the Capital-Using Enterprise, Harvard University Press, Cambridge, Massachusetts.

Smulders S., Michiel de Nooij, 2003, The impact of energy conservation on technology and economic growth, Resource and Energy Economics 25, 5979 .

Solow, R.M., 1956, A contribution to the Theory of Economic Growth, Quarterly Journal of Economics, 70, 1 (February), 65-94.

Solow, R.M., 1957, Technical Change and the Aggregate Production Function, Review of Economics and Statistics, 39 (August), 312-320.

Swan, T.W., 1956, Economic Growth and Capital Accumulation, Economic Record, 32, (November), 334-361.

Terborgh G., 1949, Dynamic Equipment Policy, Machinery and Allied Products Institute, Washington D.C, McGraw-Hill Book Company, Inc.

Xepapadeas A., 2003, Economic Growth and the Environment, Handbook of Environmental Economics, edited by Karl-Göran Mäler and Jeffrey Vincent. 